\title{
Discussion Report: Formation of Companies
}

\author{
by
}

ANDREA FröHLICH ${ }^{1}$

The workshop on Chapter 2 regarding Formation of Companies was chaired by Andres Vutt. This report summarizes the major points made by the speaker Blanaid Clarke, the discussants Luis Fernández del Pozo and Rudolf Kaindl and the brief discussion period.

Clarke presented the key aspects of the formation of companies including the method of formation, the founders, the instrument of incorporation, the articles of association, the time of formation and the name and the share capital. Regarding the formation process she pointed out that the distinction between the terms "founders" and "subscribers" might be confusing. Further attention should be paid to the director's liability in the incorporation procedure: the duties and possible liability of the directors begin at the signing of the instrument of incorporation; the automatic assumption of liabilities by the company is initiated, however, not before the registration. The time of registration may not exceed four weeks after the date of the operative resolution. The function of the registrar, however, is purely administrative.

Prof. Clarke also addressed the rules concerning share capital and the payment for shares. In accordance with the Second European Company Law Directive (Directive 2012/30/EU), the $€ 25,000$ minimum capital requirement in public limited companies ensures a level of creditor protection, whereas the share capital in private limited companies can be freely decided. Regarding the consideration for shares, she points out that both nominal value or no-parvalue shares are permitted, however there exists a prohibition on issuing shares at a discount.

Fernández del Pozo discussed a number of points regarding the chapters on formation and registration of companies. He submits that a distinction between the two concepts of the "Instrument of Incorporation" (Section 3) and the "Articles of Incorporation" (Section 4) should be avoided. He agrees with Prof. Clarke on the confusing distinction between "formation" and "registration" and proposes a clearer definition of these terms in the final EMCAversion. Moreover, he proposes the use of full online-registration. Regarding the "lapse" of the company in case of non-appropriate registration within the

1 PhD Candidate, University of Würzburg. 
legal time limit, the legal meanings and consequences need to be concretized. Furthermore, from his perspective the admission of no-par-value shares seems to represent a violation of the Second European Company Law Directive (2012/30/EU).

Kaindl focused his contribution upon the aspect of online registration. In Austria electronic registration is reserved to notaries who also give the necessary legal advice before a company is founded. The registration time is around five days - in contrast, the EMCA-draft stipulates a four week registration period. The Austrian model offers a legally supervised formation procedure which is not granted by the EMCA. Furthermore, he points out that a template might be sufficient for wholly owned companies, but in case of several shareholders, there are more individual issues at play, which cast doubt upon the ability of a template to result in the desired success. Dr. Kaindl stressed that the success of a company is not ensured by the registration process, but rather by a prudent business plan.

The following discussion concentrated upon three elements:

\section{1) Registration Procedure}

Concerning the registration procedure, possible pros and cons of online registration were discussed. The EMCA-Draft opts for a completely electronic registration system which stands in contrast to the traditional ideas of company registration in the continental member states. From the audience, it was emphasized that the EMCA is not a harmonization instrument but only an academic proposal, which doesn't change the system in practice.

Furthermore, it was clarified that the time of four weeks until registration is stipulated as a deadline ("no later than four weeks"), i.e. the registration time may be shorter.

\section{2) Shareholder Agreement}

In the current version of the EMCA, there is no provision regarding shareholder agreements. This has to be improved and expressed more clearly.

3) Admission of No-Par-Value Share System

Finally, the admission of value and no-par-value shares was discussed. Whereas some participants expressed doubts on the co-existence of these two share systems, Vutt informed the workshop that the provision in the EMCA originates from Finish law and is not a contravention of EU law. In consequence, this system could not be regarded as illegal. 